\title{
Synthesis and monolayer study of a new amphiphilic photochromic crown-ether
}

\author{
S.Yu. Zaitsev a, * T.I. Sergeeva a , E.A. Baryshnikova a , W. Zeiß ${ }^{\text {b }}$, D. Möbius ${ }^{\text {b }}$, \\ O.V. Yescheulova ${ }^{c}$, S.P. Gromov ${ }^{\mathrm{c}}$, O.A. Fedorova ${ }^{\mathrm{c}}$, M.V. Alfimov ${ }^{\mathrm{c}}$ \\ a Institute of Bioorganic Chemistry, Russian Academy of Sciences, Miklucho-Maklaya Str. 16 / 10, Moscow 117871, Russian Federation \\ ${ }^{\mathrm{b}}$ Max-Planck-Institut für biophysikalische Chemie, Postfach 2841, 37018 Göttingen, Germany \\ ${ }^{\mathrm{c}}$ Institute of Chemical Physics, Russian Academy of Sciences, Kosygin Str. 4, Moscow 117334 Russian Federation
}

\begin{abstract}
The ionoselective and photosensitive properties of the new amphiphilic crown-ether dye \{perchlorate of 2-[( E)-2-(2,3,5,6,8,9,11,12-octahydro-1,4,7,10,13-benzopentaoxacyclopentadecin-15-yl)]-5-octadecanoylamino-3-ethyl-1,3-benzothiazolium\} in monolayers have been studied. The collapse pressure of the dye monolayers is about $53 \mathrm{mN} / \mathrm{m}$ on distilled water, slightly increases up to $57-59 \mathrm{mN} / \mathrm{m}$ in the presence of $\mathrm{Na}^{+}, \mathrm{Ca}^{2+}, \mathrm{Mg}^{2+}$ cations and significantly decreases up to $43-44 \mathrm{mN} / \mathrm{m}$ in the presence of $\mathrm{K}^{+}$cations in the aqueous subphases. The area per dye molecule in monolayer is the smallest on water and increases with increasing of the salt concentration in the aqueous subphase. These are evidences for the existence of the dye-cation complexes in monolayers. The reversible changes of the reflection intensity (trans-cis-trans isomerization) by dye photoactivation can be observed only for the dye-cation complexes at very low surface pressure in the liquid-expanded state of monolayers. The changes of the reflection intensity by photoactivation in the liquid-condensed state of the dye monolayers on $\mathrm{KCl}$ solution are found irreversible that may be due to the photodimerization of the dye to cyclobutane. (C) 1999 Elsevier Science S.A. All rights reserved.
\end{abstract}

Keywords: Monolayers; Photochromic crown-ether

\section{Introduction}

The synthesis of various crown-ethers with additional photosensitive, self-assembly or polymerizable fragments in the molecule is a quickly growing field of modern research. The mono- and bilayer films based on these "supermolecules" can serve as unique models for the investigation of various processes in biological membranes and are promising as technical materials with particular properties. The main investigations on monolayers and Langmuir-Blodgett films of various crown-ethers, including photosensitive and self-assembly fragments, are summarized and discussed in the recent review of Lednev and Petty [1].

In our recent studies [2-4], a series of crown-ethers, containing fatty alkyl chains as substitution in the benzothiazolium styryl fragment of the molecule, has been prepared. The ionoselective and photosensitive properties of these amphiphilic crown-ethers in monolayers were inves-

\footnotetext{
* Corresponding author. Tel.: + 7-95-3360600; fax: +7-95-3351011; E-mail: szaitsev@ibch.siobc.ras.ru
}

tigated in the presence of various cations in the aqueous subphase. The aim of this work is the preparation and monolayer study of a new photochromic crown-ether, containing fatty alkyl chain as substitution in the benzyl ring of the molecule.

\section{Experimental}

The new amphiphilic benzo-15-crown-5 styryl dye \{perchlorate of 2-[(E)-2-(2,3,5,6,8,9,11,12-octahydro1,4,7,10,13-benzopentaoxacyclopentadecin-15-yl)]-5-octadecanoylamino-3-ethyl-1,3-benzothiazolium\} has been synthesized according to Scheme 1 and methods described in Ref. [2].

The structure of the resulting compound has been confirmed by ${ }^{1} \mathrm{H}$ NMR spectroscopy. The data of elemental analysis correspond to the assumed structure. Judging from the coupling constants of olefinic protons the resulting photochromic crown-ether dye $\mathbf{3}$ has the trans-configuration.

Monolayers of photochromic crown-ether dye $\mathbf{3}$ have been prepared and studied on commercial film balances 
("Lauda', FRG and "NIMA-NFT", UK-FRG). The samples of crown-ether ( $10 \mu \mathrm{l}$ from $1 \mathrm{mM}$ solution) have been spread onto water or $1.0 \mathrm{mM}$ salt solutions between moving and measuring barriers at $18^{\circ} \mathrm{C}$. The prepared monolayers have been compressed by a moving barrier with constant speed of about $1 \mathrm{~cm}^{2} / \mathrm{s}$ and the isotherms of surface pressure $(\pi)$-molecular area $(A)$ and surface potential-molecular area of the monolayer have been recorded.

\section{Results and discussion}

The new photochromic crown-ether forms stable insoluble monolayers on distilled water and aqueous salt subphases. The collapse pressure of the dye monolayers is about $53 \mathrm{mN} / \mathrm{m}$ on distilled water and slightly increases up to $57-59 \mathrm{mN} / \mathrm{m}$ in the presence of $\mathrm{Na}^{+}, \mathrm{Ca}^{2+}, \mathrm{Mg}^{2+}$ cations, respectively, in the aqueous subphases (Fig. 1). In contrast, collapse pressure of the dye monolayers is decreasing to a value of $43-44 \mathrm{mN} / \mathrm{m}$ in the presence of $\mathrm{K}^{+}$ cations in the aqueous subphase (Fig. 1). The area per molecule of the dye in the liquid-condensed state of the monolayer is smallest on water and increases with increasing the salt concentration in the aqueous subphase. For example, at $30 \mathrm{mN} / \mathrm{m}$ the values of the area are 0.32 $\mathrm{nm}^{2} /$ molecule on distilled water, $0.36,0.38,0.38$ and 0.40 $\mathrm{nm}^{2} /$ molecule on $1 \mathrm{mM}$ solutions of $\mathrm{NaCl}, \mathrm{CaCl}_{2}, \mathrm{MgCl}_{2}$ and $\mathrm{KCl}$, respectively. This is evidence for the existence of the dye-cation complex in the liquid-condensed monolayer, but the conformations of the polyether ring of the dye molecules are slightly different depending on the particular cation incorporated into the monolayer from the aqueous subphase. This is especially pronounced for the monolayers of the dye in the liquid-condensed state on $\mathrm{KCl}$ (Fig. 1, curve 5), where also the shape of the isotherm is rather different from those on the distilled water and other cation solutions (Fig. 1, curves 1-4), because of the strong interaction of $\mathrm{K}^{+}$with the polyether ring of the dye molecule.

It is important that the areas per molecule of the dye in the liquid-condensed state of the monolayer on water and various salts are smaller by a factor of 2 compared to those of the previously prepared and studied dyes with fatty acid chains attached to the ammonium nitrogen [2-4]. According to estimations on the Stuard molecular models, the areas of about $0.35 \mathrm{~nm}^{2} /$ molecule are close to the minimal cross-section of the styryl fragment. Thus, the styryl fragment and fatty chain of the dye molecule must be oriented vertically towards the interface in contrast to the previously studied crown-ether dyes [3] whose styryl fragment was at a tilt of about $51^{\circ}$ towards the interface.

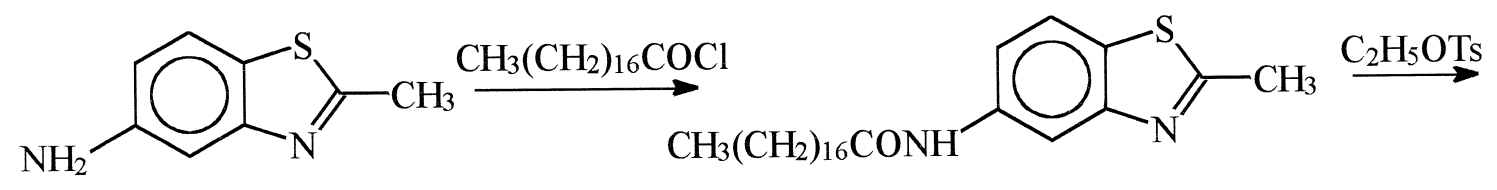<smiles>CCCCCC(C)(C)C(=O)Nc1ccc2sc(C)[n+](CC)c2c1</smiles><smiles></smiles><smiles>[R]c1ccc2sc(/C=C/c3ccc(OCCOCCOCC)c(OCCOCC)c3)[n+]([R2])c2c1</smiles>

$$
\text { 3, } \mathrm{R}^{1}=\mathrm{NHCO}\left(\mathrm{CH}_{2}\right) 16 \mathrm{CH}_{3}, \mathrm{R}^{2}=\mathrm{C}_{2} \mathrm{H}_{5}, \mathrm{n}=1 \text {. }
$$

Scheme 1. Synthesis of a new amphiphilic photochromic crown-ether (3) by reaction of the active methylene group of benzothiazolium salt (1) with the formyl derivative of benzo-15-crown-5 (2). 


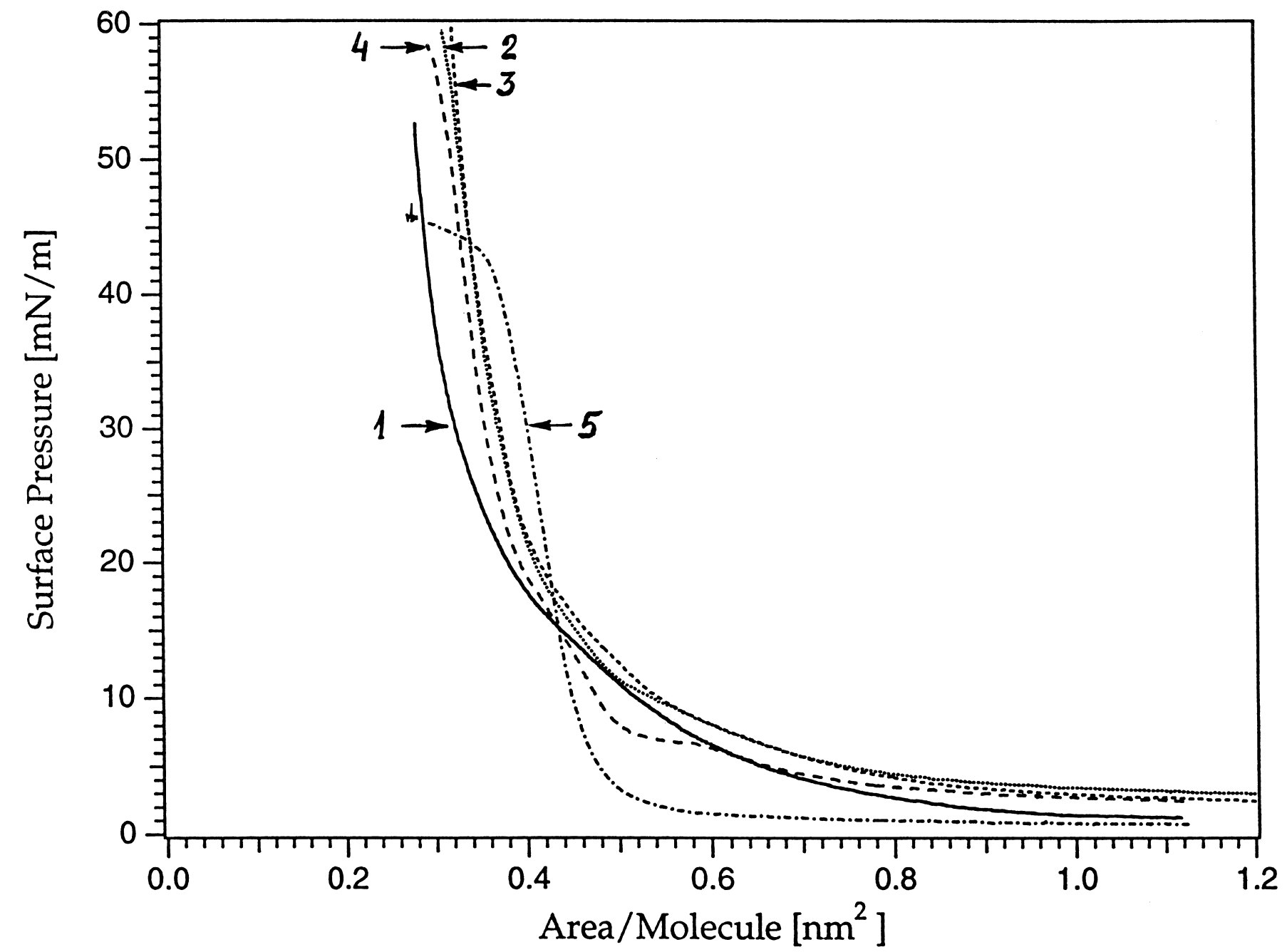

Fig. 1. Surface pressure-molecular area isotherms of the crown-ether dye monolayers on water (1) and $1 \mathrm{mM}$ solutions of $\mathrm{CaCl}_{2}(2), \mathrm{MgCl}_{2}(3), \mathrm{NaCl}(4)$ and $\mathrm{KCl}(5)$ at $18^{\circ} \mathrm{C}$. 


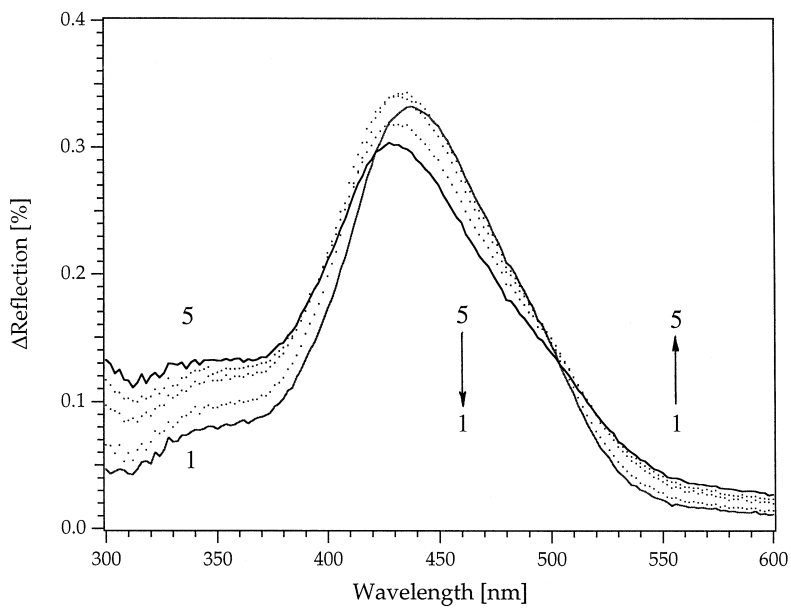

Fig. 2. Reflection spectra of the crown-ether dye monolayers on water at 5 (1), $10(2), 20(3), 30(4)$ and $40 \mathrm{mN} / \mathrm{m}$ (5).

The reflection spectra (plotted as difference $\Delta R$ of the reflectivity of the monolayer-covered subphase and that of the clean subphase [5]) of the dye monolayers on distilled water and various salts show a strong band in the range of $400-500 \mathrm{~nm}$ and a less intense band at 330-370 nm wavelength (Fig. 2). The reflection maximum for the dye monolayers on distilled water is about $438 \mathrm{~nm}$ at $5 \mathrm{mN} / \mathrm{m}$ which is a little bit lower than that of the dye solution in chloroform. There is a pronounced shift of the maximum position from 438 to $426 \mathrm{~nm}$ for the dye monolayers on water when the surface pressure is increased from 5 to 40 $\mathrm{mN} / \mathrm{m}$. We ascribe this effect to an aggregation of the dye molecules in the monolayer by interaction of positively charged ammonium groups of one dye molecule with the crown-ether ring of its neighbour, as suggested in a previous work [1], especially at high surface pressures. There is almost no shift of the reflection band maximum for the dye monolayers in the presence of alkali metal cations in the aqueous subphase (data not shown here) indicating an

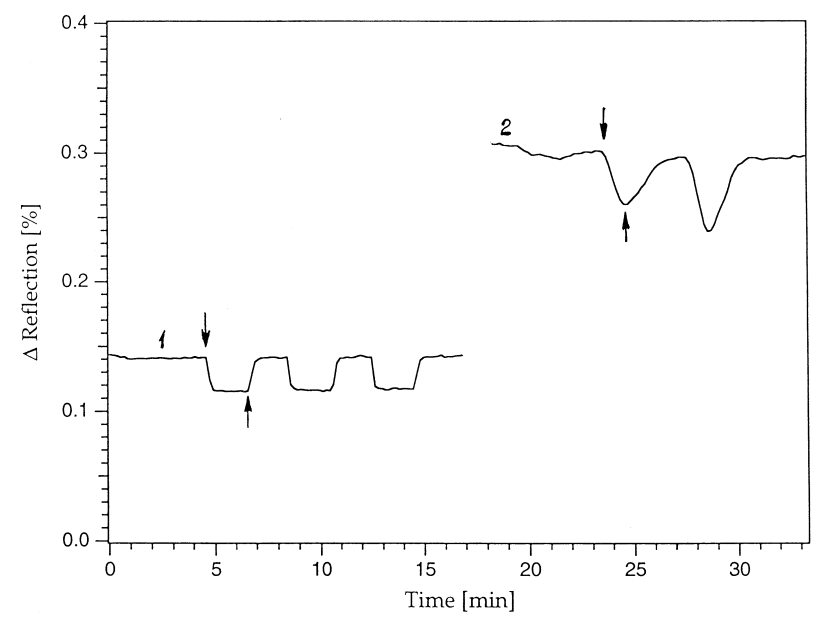

Fig. 3. Reversible changes of the reflection intensity at $440 \mathrm{~nm}$ for the dye monolayers on $10 \mathrm{mM} \mathrm{NaCl}$ at $1.0 \mathrm{mN} / \mathrm{m}$ (1) and $10 \mathrm{mN} / \mathrm{m}$ (2) by illumination with $438 \mathrm{~nm}$ and dark relaxation ( $\downarrow$ : light on, $\uparrow:$ light off).

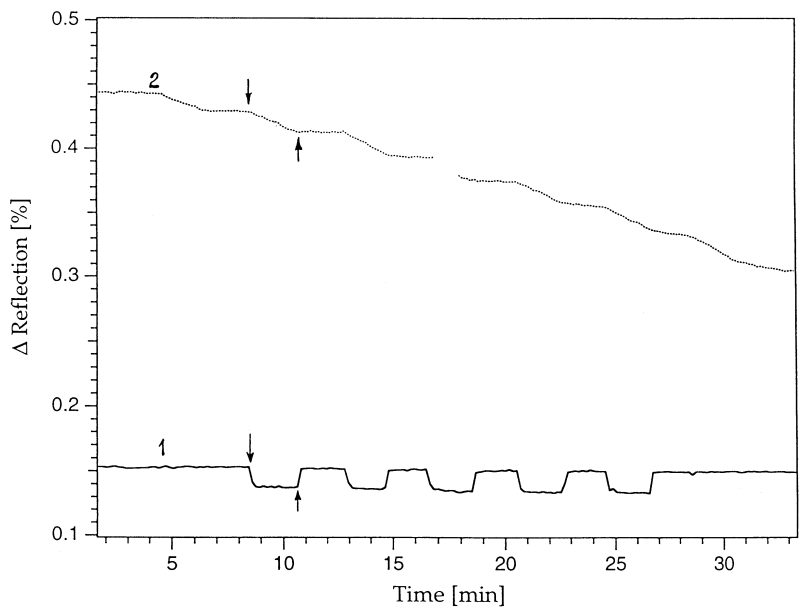

Fig. 4. Reversible changes of the reflection intensity at $440 \mathrm{~nm}$ for the dye monolayers on $10 \mathrm{mM} \mathrm{KCl}$ at $1.0 \mathrm{mN} / \mathrm{m}$ (1) and $10 \mathrm{mN} / \mathrm{m}$ (2) by illumination with $438 \mathrm{~nm}$ and dark relaxation ( $\downarrow$ : light on, $\uparrow$ : light off).

inhibition of dye aggregation due to complexation of dye with cations from aqueous subphase.

The dye monolayers in the liquid-expanded state (low surface pressures) and in the presence of $\mathrm{K}^{+}$or $\mathrm{Na}^{+}$ cations in the aqueous subphases (Figs. 3 and 4, curve 1) show a sharp decrease of reflection intensity at the maximum of the main band at $440 \mathrm{~nm}$ within a few seconds by illumination with light of wavelength $438 \mathrm{~nm}$, i.e., close to the maximum of the band. When the reflection intensity $\Delta R$ has become constant, the light is switched off, and an increase of the reflection intensity is observed to almost the initial values (Figs. 3 and 4, curve 1). These reversible changes of the reflection intensity are found only at low surface pressures (in the liquid-expanded state of the monolayer) and are due to the trans-cis and cis-trans isomerizations of the $\mathrm{C}=\mathrm{C}$ bound in dye molecule. In contrast, by increasing the surface pressure the dye monolayers on $\mathrm{NaCl}$ (Fig. 3, curve 2) show another type of reversible change (with slow kinetics). Moreover, the changes of the reflection intensity in the presence of $\mathrm{KCl}$ are found to be irreversible in the liquid-condensed state of the monolayer (Fig. 4, curve 2). These effects and completely irreversible changes of the reflection intensity by the dye photoactivation in the liquid-condensed state of monolayers may be due to the photodimerization of the dye to cyclobutane.

Thus, the reversible changes of the reflection intensity (trans-cis-trans isomerization) can be observed only for complexes of the dye molecules at very low surface pressure in the liquid-expanded state of monolayers with cations from the aqueous subphase.

\section{Acknowledgements}

This work was supported by grants from the Deutsche Forschungsgemeinschaft (FRG), INTAS and Russian Foundation of Basic Research (Russia). 


\section{References}

[1] I.K. Lednev, M.C. Petty, Adv. Mater. 8 (1996) 615-630.

[2] S.Yu. Zaitsev, V.P. Vereschetin, S.P. Gromov, O.A. Fedorova, M.V. Alfimov, H. Huesmann, D. Möbius, Supramol. Sci. 4 (1997) 519-524.

[3] S.Yu. Zaitsev, S.P. Gromov, O.A. Fedorova, E.A. Baryshnikova, V.P.
Vereschetin, W. Zeiß, H. Huesmann, M.V. Alfimov, D. Möbius, Colloids Surf. 131 (1998) 325-332.

[4] S.Yu. Zaitsev, E.A. Baryshnikova, V.P. Vereschetin, S.P. Gromov, O.A. Fedorova, M.V. Alfimov, H. Huesmann, D. Möbius, Thin Solid Films 327/329 (1998) 821-823.

[5] M. Orrit, D. Möbius, U. Lehmann, H. Meyer, J. Chem. Phys. 85 (1986) 4966-4979. 